\title{
RUPTURED HEPATIC HYDATID CYST : A RARE CASE REPORT
}

\begin{tabular}{ll}
$\begin{array}{l}\text { Dr syed md } \\
\text { sharique* }\end{array}$ & $\begin{array}{l}\text { MBBS , PG student 3rd yr General Surgery,rims,Ranchi. }{ }^{*} \text { Corresponding } \\
\text { Author }\end{array}$ \\
\hline $\begin{array}{l}\text { Dr Mritunjay } \\
\text { Sarawagi }\end{array}$ & MBBS, MS, Professor, Rims, Ranchi. \\
\hline Dr Anjay Kumar & MBBS, MS, Asso. Professor, Rims, Ranchi. \\
\hline
\end{tabular}

ABSTRACT Hydatid cyst rupture into abdomen is a serious complication in cystic hydatid disease of liver. Both microscopic or macroscopic rupture can occur and it is fatal without surgery. It is primarily caused by tapeworm (ECHINOCOCCUS GRANULOSUS) and occurs worldwide with an incidence of 200/100,000in endemic areas. This is a case of 28 yr. female presenting with sudden onset pain abdomen since 4 days. Abdominal ultrasonography demonstrates ruptured hepatic hydatid cyst with free peritoneal fluid. She was managed in emergency operation theatre due to her clinical condition and exploratory laparotomy with omentopexy and toileting were done after fluid resuscitation, antihistaminic and corticosteroid treatment. Postoperatively she received antihelminthic treatment with Albendazol. She made a good recovery following surgery.

$\begin{array}{ll}\text { KEYWORDS : } \\ \text { INTRODUCTION } & \begin{array}{l}\text { general condition after fluid resuscitation, antihistaminic and } \\ \text { corticosteroid treatment .During surgery approximately 3.5-4 }\end{array} \\ \text { Echinococcosis of the liver is a parasitic infection primarily } & \begin{array}{l}\text { litre of collected fluid were aspirated .hepatomegaly of left } \\ \text { caused by the larvae of the cestode Echinococcus granulosus. }\end{array} \\ \text { This tapeworm is responsible for cystic hydatid disease } & \text { lobe was noticed. large cavity of approximately l-1.5 litre } \\ \text { (Cystic Echinococcosis), which is the most common form }{ }^{1} . & \text { present behind GB involving segment 4,7\&8 lobe of liver with } \\ \text { Worldwide incidence is between l and } 200 \text { per } 100,000^{1} \text {.Adult } & \text { multiple daughter cyst were found whole cavity was cleaned } \\ \text { cestode develops in the small intestine of definitive host } & \text { with 10\% betadine ointment followed by } 2 \text { ROMOADK drain } \\ \text { commonly dog and released egg which is dispersed in the } & \text { was applied in pelvis and near GB respectively. ometopexy in } \\ \text { stool of the dog. Humans act as "aberrant" intermediate hosts } & \text { cavity was done followed by abdominal closure with } \\ \text { by accidentally ingesting eggs via infected vegetables or } & \text { haemostasis achieved.Postoperative period were uneventful } \\ \text { water, or touching dogs with contaminated hair } 1,3 \text {. The most } & \begin{array}{l}\text { \& was treated with continuous albendazole for } 2 \text { months } \\ \text { following from her postoperative day. } 2\end{array}\end{array}$

(up to $25 \%{ }^{[5]}$ ) is the second most common site. Less frequently cysts develop in the spleen, kidneys, heart, bones, and central nervous system ${ }^{[4]}$. Cyst may be located in any are of the liver and can be solitary or multiple.it can contain several volume of fluid containing protoscoliosis. ${ }^{[4]}$ risk of rupture is associated with young age, superficial localisation, trauma, and large size ${ }^{[5]}$. Rupture can result in complications including abdominal pain, anaphylaxis, and death.

\section{CASEREPORT}

A $28 \mathrm{yr}$. old female presented to rims surgery emergency with complain of sudden onset of pain abdomen since 4 days \& abdominal distension since 2 days. There was no history of trauma or any past medical history of note. At presentation, she was haemodynamically stable with a pulse rate of $96 \mathrm{bpm}$ and blood pressure of $108 / 68 \mathrm{mHg}$. There was no respiratory compromise and $\mathrm{O} 2$ saturation was $98 \%$ on room air. Her temperature was $36.9^{\circ} \mathrm{C}$. On physical examination icterus was present with bilateral limb oedema .she was well oriented with time, place, and surrounding.

on local examination: mild distension was present in all quadrant .On her routine examination $\mathrm{Hb}$ was 10.5 , her TLC was 23600 with neutrophil at 90.7\& lymphocytes at 5.5.her liver function report was deranged with S.Albumin at 2,GGT at 95,SGOT-212,SGPT-89, SAP-131,ESR-50,S.CALCIUM-7.3

USG finding states a well defined hypoechoic cystic lesion with interval debris noted in right lobe of liver spanning $\mathrm{V}$, VI,VII segments with free fluid noted in peritoneum suggestive of ruptured hydatids cyst.

She was shifted to casualty OT and planned for exploratory laparotomy with omentopexy and toileting due to patient

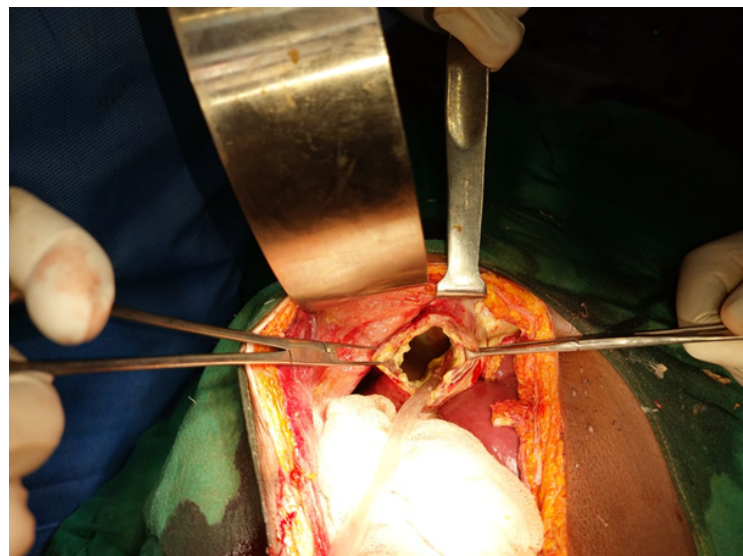

Figure 1 intraoperative ruptured hydatid cyst cavity.

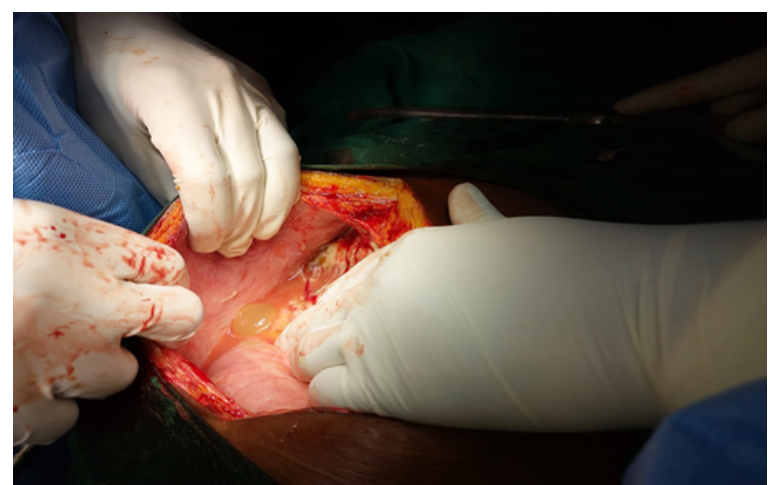

Figure 2 Intraoperative Image Showing Daughter Cyst. 


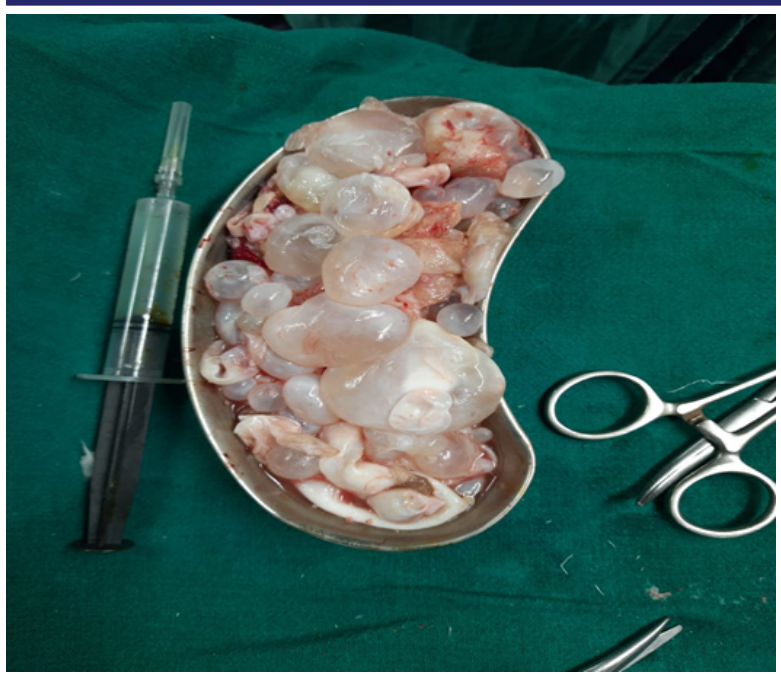

Figure 3: EXCISED HYDATID CYST

\section{DISCUSSION}

Hepatic hydatid cysts may remain clinically silent for many years and are often an incidental finding on ultrasound performed for another reason ${ }^{[2]}$. The diagnosis is often made when any complications such as jaundice or rupture or secondary infection happened ${ }^{[2]}$. In $36-40 \%$, at the time of diagnosing cysts are found to be ruptured or secondarily infected ${ }^{[2]}$. It is rarely palpated as mass before the cyst reaches $20 \mathrm{~cm}$ in diameter ${ }^{[2]}$. Cysts close to the peritoneal cavity may rupture into the free peritoneum, or less commonly the gastrointestinal tract or right renal pelvis ${ }^{[2]}$ and may lead to development of extrahepatic cysts .It can also cause symptoms of an allergic origin such as marked eosinophilia, urticaria or anaphylaxis. More commonly, rupture occurs into bile ducts resulting in biliary obstruction, cholangitis, or biliary colic ${ }^{[2]}$. Marked elevations of bilirubin and alkaline phosphatase are seen in these cases ${ }^{[7]}$. It may also erode through the diaphragm and rupture into the pleural or pericardial cavities, lung, or bronchi ${ }^{[1]}$. In $5-40 \%$ of patients cyst suppuration has been observed ${ }^{[1]}$. Glomerular deposits of hydatid antigen may result in membranous glomerulonephritis ${ }^{[3]}$ [3]. The key tools for diagnosis are imaging and serology. Abdominal ultrasound is considered the gold standard ${ }^{[1]}$ as it is non-invasive, inexpensive and can visualise the cysts immediately. MRI is preferable to $\mathrm{CT}$, particularly for presurgical evaluation ${ }^{[1]}$ as it gives better visualisation of liquid areas within the cyst. Several serological tests are available, but IgG ELISA to the antigen Brich fraction is the most sensitive (>95\%) and specific ${ }^{[7]}$ Hepatic cysts are more likely to elicit an immune response ${ }^{[4]}$ Eosinophilia of greater than $7 \%$ is found in $30 \%$ of patients ${ }^{[3]}$ Treatment are done with the main aims to eliminate the parasite and to prevent recurrence, in order to minimise morbidity and mortality risk ${ }^{[1]}$. Medical treatment with the benzimidazole Albendazole cannot be regarded as definitive treatment alone ${ }^{[3]}$. Albendazole has better absorption than other benzimidazoles but many months of therapy are still required, occasionally in conjunction with Praziquantel ${ }^{[7]}$. Generally, 30\% of cysts disappear, 30-50\% degenerate, and $20-40 \%$ remain unchanged ${ }^{[3,4]}$. Surgical management of unruptured cysts ranges from radical (such as pericystectomy or liver resection) to conservative (de-roofing, marsupialisation or capitonnage) using open or laparoscopic techniques ${ }^{[1,4,5]}$. Radical techniques have a lower recurrence rate but carry higher operative risk. Overall recurrence rates vary from $2 \%$ to $25 \%$, and operative mortality ranges from $0.5 \%$ to $4 \%{ }^{[1,4]}$. Partial hepatectomy is advocated for cysts that involve the left lateral segment, with a recurrence rate of $8-22 \%{ }^{\text {I2 }}$. Adjunctive benzimidazoles are used to reduce the risk of anaphylaxis and dissemination. Surgical removal of all cysts with associated chemotherapy should be the ideal therapeutic option ${ }^{[6,8]}$. More recently, percutaneous techniques such as PAIR ("Puncture-Aspiration-Injection-Reaspiration") have been developed, which may be comparable or even superior to surgery ${ }^{[9]}$. The most frequent sites of rupture are the biliary tract $(12 \%)$ and thorax $(2.2 \%){ }^{[8]}$. In some rare cases intrabiliary and intraperitoneal rupture simultaneously are seen ${ }^{[10]}$. Intraperitoneal rupture is a rare but serious complication of hepatic Cystic Echinococcosis and presents a unique challenge to the surgeon. In a large multicentre retrospective study intra peritoneal rupture are seen in $1.6 \%{ }^{[8]}$. Risk factors include young age, a cyst diameter of more than $10 \mathrm{~cm}$, and superficial cyst location ${ }^{[5]}$. Rupture is unpredictable and can occur either spontaneously ${ }^{[10-12]}$, or as a result of trauma ${ }^{[5,6,13,14]}$ or iatrogenic. Although trauma is the most frequent cause ${ }^{[5]}$. It has an usual presentation of an acute abdomen requiring emergency surgery to remove the intraperitoneal fluid and eradicate the cysts ${ }^{[6,8,10,11]}$. However, rupture can cause only minimal symptoms or can even be clinically silent, presenting years later with disseminated intra-abdominal disease ${ }^{[8]}$. After intraperitoneal rupture of liver cysts, mortality rates of $0-23.5 \%$ have been reported ${ }^{[11,15]}$. Morbidity ranges from $20 \%$ to $\left.35.3 \%{ }^{[8,15}\right]$, with cited recurrence rates between $6.7 \%$ and $28.6 \%$ of cases ${ }^{[6,11]}$. Intraperitoneal rupture of a cyst is difficult to cure due to the remaining protoscolices forming extrahepatic daughter cysts and since recurrence is almost inevitable, benzimidazoles are essential in these cases [2]. Ruptured cysts fall into three categories: contained, communicating, and direct ${ }^{[16]}$. Contained rupture involves only the endocyst and the cyst contents remain within the confines of the pericyst. Communicating rupture involves tear of the endocyst with escape of contents via biliary radicules (or bronchioles) that have been incorporated into the pericyst. Tear of the pericyst and endocyst allowing spillage of contents into the peritoneal or pleural cavity is direct rupture ${ }^{[13]}$. Anaphylaxis is a rare $\left(1-12.5 \%^{[5,6]}\right.$ ) but recognised sequela of cyst rupture and can occur after all types of rupture. Less severe allergic reactions can occur in up to $25 \%$ of patients with intraperitoneal rupture of cysts ${ }^{[6]}$.

\section{CONCLUSION}

Although rare, intraperitoneal rupture of hepatic (or indeed non-hepatic) cysts is a life-threatening complication of Cystic Echinococcosis as it causes serious haemodynamic instability and allergic reactions.It should be included in the differential diagnosis of patients in endemic areas presenting with an acute abdomen. Anaphylaxis or severe allergic reaction may be the only presenting feature in ruptured cysts, especially after trauma, and should again raise suspicion in patients from endemic areas, especially if no other cause is evident.

\section{REFERENCES}

[1] G. Nunnari, M. R. Pinzone, S. Gruttadauria et al., "Hepatic echinococcosis: clinical and therapeutic aspects," World Journal of Gastroenterology, vol. 18, no. 13, pp. 1448-1458, 2012.

[2] N. McIntyre, J.-P Benhamou, J. Bircher, M. Rizzetto, and J. Rodes, Eds., Oxford Textbook of Clinical Hepatology, vol. 1, 1991

[3] S. Sherlock and J. Dooley, Diseases of the Liver and Biliary System, 11th edition, 2002.

[4] P. Moro and P. M. Schantz, "Echinococcosis: a review," International Journal of Infectious Diseases, vol. 13, no. 2, pp. 125-133, 2009

[5] A. Akcan, H. Akyildiz, T. Artis et al., "Peritoneal perforation of liver hydatid cysts: clinical presentation, predisposing factors, and surgical outcome," World Journal of Surgery, vol. 31, no. 6, pp. 1284-1291, 2007.

[6] M. Yilmaz, S. Akbulut, A. Kahraman, and S. Yilmaz, "Liver hydatid cyst rupture into the peritoneal cavity after abdominal trauma: case report and literature review,"International Surgery, vol. 97, pp. 239-244, 2012.

[7] T. D. Boyer, T. L. Wright, M. P. Manns, and D. Zakim, Zakim and Boyer's Hepatology, 5th, 2006.

[8] C. Dziri, K. Haouet, A. Fingerhut, and A. Zaouche, "Management of cystic echinococcosis complications and dissemination: where is the evidence?" World Journal of Surgery, vol. 33, no. 6, pp. 1266-1273, 2009

[9] R. A. Smego, S. Bhatti, A. A. Khaliq, and M. A. Beg, "Percutaneous aspirationinjection-reaspiration-drainage plus albendazole or mebendazole for hepatic cystic echinococcosis: a metaanalysis," Clinical Infectious Diseases, vol. 37, no. 8, pp. 1073- 1083, 2003.

[10] P. J. Marriott, J. Karani, S. B. Lucas, P. L. Chiodini, and N. D. Heaton "Anaphylaxis from intravascular rupture of hydatid disease following liver trauma,"Journal of Surgical Case Reports, vol. 7, no. 1, 2010 
[11] A. Sumer, K. Caglayan, E. Altinli, and N. Koksal, "Case report: spontaneous liver hydatid cyst rupture in a child," Israeli Journal of Emergency Medicine, vol. 9, no. 1, pp. 13-16, 2009.

[12] D. Castanares-Zapatero and P. F. Laterre, "Ruptured hydatid cyst in a patient with shock," Hepatobiliary and Pancreatic Diseases International, vol. 8, no. 6, pp. 638-639, 2009.

[13] M. Elmali, M. Ceyhan, M. Ilgar, C. Koprulu, M. Ozfindik, and R. Sancak, "Hepatic hydatid cyst rupture and anaphylaxis after a fall," Indian Journal of Pediatrics, vol. 76, no. 3, pp. 329-330, 2009. 